\title{
The emerging role of nimotuzumab in the treatment of non-small cell lung cancer
}

\author{
This article was published in the following Dove Press journal: \\ Biologics:Targets \& Therapy \\ 8 November 2010 \\ Number of times this article has been viewed
}

\section{William Boland' \\ Gwyn Bebb2,3 \\ 'Department of Anatomy and Cell Biology, McGill University, Montreal, Quebec, Canada; ${ }^{2}$ Tom Baker Cancer Centre, Calgary, Alberta, Canada; ${ }^{3}$ University of Calgary, Calgary, Alberta, Canada}

\begin{abstract}
Current non-small cell lung cancer (NSCLC) chemotherapy and radiotherapy regimens, although showing definite survival benefit, still leave patients with a disappointing $15 \% 5$-year overall survival rate. Because of the need to improve traditional outcomes, research has focused on identifying specific tumorigenic pathways that may serve as therapeutic targets. The most successful strategies to date are those aimed at the epidermal growth factor receptor (EGFR), which is found to be upregulated in $40 \%-80 \%$ of NSCLC. Several tyrosine kinase inhibitors and monoclonal antibodies (mAbs) have been developed that inhibit the EGFR receptor and have demonstrated clinical benefit in trials as single agents and in combination regimens. Here we discuss one such agent, the mAb nimotuzumab, the background of its development, its clinical experience in NSCLC thus far, and the rationale for expanding its use to other NSCLC treatment settings.
\end{abstract}

Keywords: non-small cell lung cancer, chemotherapy, radiotherapy, overall survival, EGFR

\section{Introduction}

Lung cancer remains the primary source of cancer mortality worldwide and continues to increase in incidence in developing countries such as India and China. ${ }^{1,2}$ Within the United States and Canada, where incidence rates are dropping, it still accounts for more deaths than the next four leading malignancies combined and recently surpassed cerebral vascular disease as the number two killer overall. ${ }^{3-5}$ As a result, treating this disease, especially non-small cell lung cancer (NSCLC), which accounts for roughly $85 \%$ of pulmonary malignancies, ${ }^{6}$ has become a major undertaking at medical centers around the world.

Standard treatment for NSCLC involves surgical resection, platinum-based chemotherapies, and radical or palliative radiotherapies, yet, prognoses have plateaued and, even for the earliest stages, remain relatively reserved. ${ }^{7}$ The five-year survival rate ranges from $49 \%$ for stage IA to $1 \%$ for stage IV disease, ${ }^{8}$ the majority of deaths being caused by distal recurrence. Underpinning this poor outcome is the tendency to establish diagnoses only at an advanced stage (in $70 \%$ of cases ${ }^{9}$ ) compounded by the comorbidities and decreased performance status of patients, who are often, or have been, chronic smokers. Given the limitations of traditional cytotoxic agents, novel targeted therapies became an exciting prospective field for NSCLC treatment in the late 90s and early 2000s. The most clinically relevant have been interventions aimed at the epidermal growth factor receptor (EGFR), including intracellularly acting tyrosine kinase inhibitors (TKIs) and the extracellular-binding monoclonal antibodies (mAbs).
Correspondence: Gwyn Bebb Tom Baker Cancer Centre, University of Calgary, Translational Research Laboratory, I33I, 29th St NW, Calgary, T2N 4N2, Alberta, Canada Tel + I 4035213166

Fax + | 403283 |65|

Email gwyn.bebb@albertahealthservices.ca 


\section{Targeting the EGFR EGFR and NSCLC}

EGFR (also HER1 or ErbB1) is a tyrosine kinase receptor and member of the ErbB family of transmembrane proteins that homodimerizes or heterodimerizes with another ErbB receptor under the influence of an extracellular agonist, usually epidermal growth factor (EGF) or transforming growth factor $\alpha .^{10}$ Extracellular substrate binding brings the intracellular tyrosine kinase domains from the two receptors into close proximity, promoting intracellular autophosphorylation at specific residues and subsequent recruitment of downstream intermediate signaling proteins. ${ }^{11}$ As part of the Ras-mitogen-activated protein kinase, Akt and phosphotidylinositol 3-kinase (PI3 K)c-Jun N-terminal kinase signaling cascades, these downstream molecules are implicated in a plethora of cellular functions, such as proliferation, angiogenesis, antiapoptosis, and cell adhesion..$^{12}$ Not surprisingly, changes to these pathways can elicit dramatic phenotypic transformation, including tumor development and evolution, by encouraging uncontrolled cell division, increased cell survival, tumor vascularization, tissue invasion, and metastases. ${ }^{12-15}$ Accordingly, dysregulation of EGFR signaling has been associated with several human cancers, stimulating an early interest in it as a target for anticancer agents. ${ }^{16,17}$ In NSCLC, aberrant EGFR signaling can be caused by an amplified gene copy number, found in $40 \%-80 \%$ of tumors, as well as the acquisition of somatic, constitutively activating mutations, the majority residing in exons 19 and 21. ${ }^{17,18}$ Additionally, EGFR can become overstimulated by greater access to its ligands, which are often overproduced in tumors. ${ }^{17}$

By whichever route EGFR becomes dysfunctional, evidence suggests that increased signaling is generally associated with more undifferentiated and advanced disease and an overall worse prognosis in certain cancers. ${ }^{19}$ Moreover, EGFR overexpression has been associated with less effective chemotherapy and radiotherapy treatments. ${ }^{20,21}$ In the case of radiotherapy, studies show that tumors may upregulate EGFR in response to DNA damage, perhaps resulting in apoptosis avoidance by increasing EGFR-dependent survival cues. ${ }^{21}$ Therefore, inhibitors of EGFR may have a potential synergistic effect with radiotherapy in addition to their inherent antineoplastic nature. However, correlations between EGFR and disease status, prognosis, or response have been contentious, especially in NSCLC. ${ }^{19}$ Nevertheless, taken in conjunction with the prevalence of EGFR upregulation in cancer and the importance of its downstream targets in tumorigenic processes, inhibition of EGFR was seen as an exciting avenue of pursuit for NSCLC in the late 1990s.

\section{Tyrosine kinase inhibitors}

Gefitinib (Iressa ${ }^{\circledR}$ ), a TKI, was the first such inhibitor of EGFR to be approved for NSCLC and was followed quickly by erlotinib (Tarceva ${ }^{\circledR}$ ). These lipid-soluble molecules block the adenosine triphosphate-binding pocket of the EGFR tyrosine kinase domain, eliminating its ability to phosphorylate targets. ${ }^{22}$ They have proven to have a beneficial role in second-line treatment of metastatic NSCLC. ${ }^{23}$ Several independent studies demonstrate that the presence of EGFRactivating mutations renders cells remarkably sensitive to these agents and underpins their clinical results, ${ }^{17,18,24,25} \mathrm{a}$ phenomenon associated with nonsmoking Asian females. ${ }^{26}$ Recent trials have confirmed the remarkable clinical activity of these agents in this setting, which as a result are now approved for use to treat metastatic NSCLC as single agents in the first-line setting of EGFR mutation-positive patients on several continents. ${ }^{27,28}$ Their role in combination with chemotherapy, however, remains unproven. ${ }^{29}$

\section{Monoclonal antibodies}

Coincident with the development of small molecular inhibitors, mAbs targeting the extracellular component of EGFR and other signaling proteins thought to be associated with tumorigenesis, such as $\mathrm{ErbB}^{30}$ and vascular endothelial growth factor (VEGF), ${ }^{31}$ were developed. The antineoplastic EGFR-binding mAbs demonstrating anticancer potential thus far include cetuximab, panitumumab, zalutumumab, matuzumab, necitumumab, and nimotuzumab. It is believed they work by attaching to extracellular EGFR epitopes and sterically hindering the protein from taking on its optimum dimerization conformation or alternatively blocking EGFR interactions, in either case, inhibiting the formation of dimers and the subsequent activation of the receptor. ${ }^{32}$ However, it is also accepted that a profound immunomodulatory effect may be a component of their antitumor activity. ${ }^{33}$

\section{Nimotuzumab}

\section{Preclinical data}

Nimotuzumab was originally isolated as a mouse immunoglobulin (Ig)G2a antibody known as R3, developed against placental-derived EGFR at the Molecular Immunology Center in Havana, Cuba. ${ }^{34}$ The R3 mAb was humanized to reduce its human immunogenicity and slow clearance from the body by grafting its complimentarity determining regions into a human $\operatorname{IgG1}$ gene to create h-R3-nimotuzumab. Recreation of 3-specific murine amino acids (Serine 75, Threonine (Thr) 76, and Thr 93) in the new antibody's variable fraction preserved their anti-EGFR activity. ${ }^{34}$ Although a 
crystallized protein model has yet to be completed, a likely hypothesis for nimotuzumab binding to domain III of EGFR's extracellular region was developed by Talavera et a ${ }^{35}$ based on observed competition with cetuximab and computer simulations. The binding affinity $(\mathrm{Kd})$ of nimotuzumab to EGFR is $4.5 \times 10^{-8} \mathrm{~m}$ and is similar to EGF's own affinity for EGFR, ${ }^{36,37}$ but is $>10$-fold less than competing mAbs, cetuximab, and panitumumab. Nimotuzumab can therefore be described as a humanized IgG1 antibody that attaches to the extracellular domain III of EGFR with a moderate affinity, blocking EGF binding and sterically hindering the receptor from exposing its dimerization motif.

Cultured cells expressing high levels of EGFR and treated with nimotuzumab show less receptor activation after being assayed with ligand. ${ }^{38}$ These in vitro results have been observed mainly in A431 cells, a vulvar epidermoid carcinoma cell line, characterized by high EGFR expression..$^{39}$ However, they have also been demonstrated in cells exhibiting wild-type and constitutively active EGFR, suggesting that nimotuzumab is equally successful at EGFR inhibition in both normal and mutant backgrounds. ${ }^{21}$ In vivo xenograft models have also confirmed this antitumor effect on A431 cells in mice, an effect similar to that induced by cetuximab in the same model. ${ }^{38}$ More recent in vivo data demonstrates significant antitumor effect of nimotuzumab in xenografts utilizing the NSCLC cell lines H460, Ma-1, and H292. ${ }^{21}$ This in vivo data hints strongly at an increasingly profound antitumor effect from nimotuzumab as the extent of EGFR expression rises from low in $\mathrm{H} 460$, to moderate in Ma-1, and to high in $\mathrm{H} 292 .{ }^{21}$

Interestingly, in vitro cells bound by nimotuzumab do not exhibit an apoptotic phenotype. ${ }^{39}$ In vivo treated tumors, on the other hand, display a 5-fold increase in apoptotic activity generating a marked tumor regression within solid A431 severe combined immunodeficiency mice carcinomas. ${ }^{39}$ This distinction between in vitro and in vivo response of nimotuzumab points toward a specific apoptotic mechanism unique to the in vivo environment. Crombet-Ramos et al ${ }^{39}$ hypothesize that a decrease in angiogenesis is the major cause of in vivo tumor cell death by diminished VEGF production, a theory that has been supported by acquired resistance in cells constitutively producing VEGF. ${ }^{40}$ However, it should be pointed out that there are many other downstream targets that have not yet been ruled out as contributors to this effect. ${ }^{41}$ Furthermore, a tumor-binding IgG1 antibody may augment any inherent antineoplastic effect by triggering the antibodydependent cell-mediated cyotoxicity immune mechanism to attack cancer cells independent of EGFR inhibition. ${ }^{38,42}$

\section{Clinical experience}

\section{Solid tumors}

Promising preclinical results with nimotuzumab led to its introduction into clinical trials in 2003, beginning with a Phase I Cuban trial. ${ }^{37}$ In this Phase I study, 12 patients were enrolled to receive a one-time dose of 50, 100, 200, or $400 \mathrm{mg}$ of nimotuzumab, and, although 7 participants experienced mild or moderate adverse reactions, in contrast to the experience with other anti-EGFR agents, none developed the classic anti-EGFR acneiform rash. Thereafter, nimotuzumab was administered to more than 9,000 recipients ${ }^{43}$ in over 30 Phase I and II trials (see Table 1) that confirm the lack of a severe skin reaction and other adverse reactions (reviewed ${ }^{44}$ ). Notably, a Canadian doseescalation Phase I study reported excellent tolerability of the drug in up to 800-mg weekly infusions, with only one dose-limiting toxicity of grade 3 fatigue being reported at the 100-mg level. ${ }^{45}$ Most other studies have mainly focused on head and neck squamous cell carcinomas (HNSCCs) ${ }^{46-49}$ and brain malignancies ${ }^{50}\left(\right.$ reviewed $\left.^{51}\right)$, where nimotuzumab has shown an efficacy equal to or greater than comparable anti-EGFR mAbs.

The largest of the Phase II trials involving nimotuzumab (BEST trial), completed at multiple centers in India, included 92 patients with HNSCC who were randomized to receive chemotherapy with nimotuzumab, chemoradiotherapy with nimotuzumab, or chemotherapy and chemoradiation alone. ${ }^{52}$ This trial demonstrated a clinically significant 30 -month survival advantage with nimotuzumab over combined chemotherapy and radiotherapy $(69.57 \%$ with nimotuzumab vs $21.74 \%$ without nimotuzumab, $P=0.0011) .{ }^{53}$ Because of these and other successful trials $\left(\right.$ reviewed $\left.^{44}\right)$, nimotuzumab has been approved for use in either HNSCCs or gliomas or both in 23 countries, including China, India, and Brazil. ${ }^{54}$

\section{Non-small cell lung cancer}

Although an occasional NSCLC patient had been enrolled into dose-escalating Phase I trials up to this point, no clear signal of efficacy could be elicited based on such small numbers. On this basis, given the molecular rationale for targeting EGFR in NSCLCs, the early success of nimotuzumab in other solid tumors, and its benign side-effect profile, nimotuzumab use was expanded to a NSCLC population.

In the first such study (see Table 2), Bebb et a ${ }^{55}$ initiated a trial investigating the feasibility of adding the anti-EGFR $\mathrm{mAb}$ to palliative radiation in NSCLC patients of varying stages (IIB, III, and IV) deemed unsuitable for radical 
Table I Trials of nimotuzumab in solid tumors (excluding NSCLC)

\begin{tabular}{|c|c|c|c|c|c|c|c|c|}
\hline Authors & Phase & Location & $\begin{array}{l}\text { No. of } \\
\text { patients }\end{array}$ & $\begin{array}{l}\text { Cancer } \\
\text { stages }\end{array}$ & ORR & DCR & MST(mo) & vs controls \\
\hline $\begin{array}{l}\text { Crombet et al }{ }^{37} \\
(2003)\end{array}$ & 1 & Cuba & 12 & $\begin{array}{l}\text { Advanced } \\
\text { epithelial }\end{array}$ & & & & \\
\hline $\begin{array}{l}\text { Winquist et } \mathrm{a}^{46} \\
\text { (2002) }\end{array}$ & I & Canada & 17 & HNSCC & $87.5 \%$ & & & \\
\hline $\begin{array}{l}\text { Crombet et al70 } \\
(2004)\end{array}$ & $\mathrm{I} / \mathrm{II}$ & Cuba & 22 & HNSCC & $\begin{array}{l}88 \% @ 200 \\
\text { or } 400 \mathrm{mg}\end{array}$ & & $\begin{array}{l}8.6 @ 50 \\
\text { and } 100 \mathrm{mg} ; \\
44.3 @ 200 \\
\text { and } 400 \mathrm{mg}\end{array}$ & \\
\hline $\begin{array}{l}\text { Rojo et a }{ }^{47} \\
(2008)\end{array}$ & I & Spain & 10 & $\begin{array}{l}\text { Advanced } \\
\text { HNSCC }\end{array}$ & $80 \%$ & & & \\
\hline $\begin{array}{l}\text { Reddy et a }{ }^{48} \\
(2007)\end{array}$ & II & India & 17 & $\begin{array}{l}\text { III or IVA, } \\
\text { HNSCC }\end{array}$ & $76 \%$ & & & $\begin{array}{l}90 \% \text { increase } \\
\text { ORR }\end{array}$ \\
\hline $\begin{array}{l}\text { Brade } \\
(2007)\end{array}$ & I & Canada & 16 & $\begin{array}{l}\text { Advanced } \\
\text { refractory } \\
\text { CRC }\end{array}$ & & $43.8 \%$ & & \\
\hline $\begin{array}{l}\text { Crombet et al }{ }^{66} \\
(2006)\end{array}$ & II & Cuba & 29 & Gliomas & $37.9 \%$ & & & \\
\hline $\begin{array}{l}\text { Crombet } \\
\text { (2008) }\end{array}$ & $\| / / I I I$ & Cuba & 65 & $\mathrm{~GB}, \mathrm{AA}$ & & $68.6 \%$ & & $\begin{array}{l}37.2 \% \text { increase } \\
\text { DCR }\end{array}$ \\
\hline $\begin{array}{l}\text { Bode } \\
(2007)\end{array}$ & II & Germany & 46 & $\begin{array}{l}\text { Pediatric } \\
\text { brain } \\
\text { cancer }\end{array}$ & $30.4 \%$ & $45.5 \%$ & 10 & $\begin{array}{l}\text { I50\% increase } \\
\text { MST }\end{array}$ \\
\hline $\begin{array}{l}\text { Bode } \\
(2008)\end{array}$ & III & Germany & 42 & $\begin{array}{l}\text { Pediatric } \\
\text { brain } \\
\text { cancer }\end{array}$ & & & & \\
\hline $\begin{array}{l}\text { Shah et al } \mathrm{a}^{76} \\
(2009)\end{array}$ & II & Canada & 61 & $\begin{array}{l}\text { Refractory } \\
\text { CRC }\end{array}$ & & $50 \%$ & 9.3 & \\
\hline $\begin{array}{l}\text { Reddy et al } \\
(2007)\end{array}$ & II & India & 20 & $\begin{array}{l}\text { III or IVA } \\
\text { HNSCC }\end{array}$ & $100 \%$ & & & $\begin{array}{l}42.9 \% \text { increase } \\
\text { in ORR }\end{array}$ \\
\hline
\end{tabular}

Notes: ORR = complete responses + partial responses. DCR = ORR + stable disease. vs controls are comparisons of nimotuzumab to non-nimotuzumab controls.

Abbreviations: NSCLC, non-small cell lung cancer; ORR, objective response rate; DCR, disease control rate; MST, median survival time; HNSCC, head and neck squamous cell carcinomas; CRC, colorectal cancer.

therapy. Significantly, this cohort presented many of the classic challenges of NSCLC patient, being elderly and of less than ideal performance status (median age of 69 years and 5 of 18 patients were Eastern Cooperative Oncology Group performance status of 2). A similarly designed Korean trial by Choi et al $^{56}$ documented almost identical results in a comparable, albeit, East Asian population. These two trials confirmed the minimal toxicity at each dose of nimotuzumab in combination with thoracic radiation, while also demonstrating favorable results compared with historical controls ${ }^{57}$ in a NSCLC setting (Table 2).

The overall impression gleaned from these studies is that nimotuzumab can be safely administered with doses of up to 36 Gy of external beam ionizing radiation with minimal skin toxicity or esophagitis in an elderly NSCLC population. The fact that similar results were obtained in a North American and a Southeast Asian setting is notable. Unfortunately, the trials were not designed to assess the efficacy of nimotuzumab as a single agent, and although there were reports of response in tumors outside the radiation field, they remain anecdotal. These results are now set to be corroborated in randomized Phase II trials currently enrolling patients in Japan, South Africa, and Canada.

\section{Brain metastases}

The evolution of brain metastases from NSCLC heralds a grave prognosis, with only radiation and steroids being the mainstay of treatment. Given the excellent tolerability of nimotuzumab and its promising efficacy in primary brain tumors, assessing its efficacy in the setting of NSCLC metastatic to brain is logical. This was first done in a Phase II Cuban trial comparing nimotuzumab and radiation in NSCLC brain metastases with radiotherapy alone. ${ }^{58} \mathrm{~A}$ preliminary report cites a disease control rate (DCR) of 91.6\% (DCR = complete responses, partial responses, and stable disease) with a statistically significant improvement over irradiation only treated patients $(P=0.0039)$. Randomized Phase II trials designed to confirm these encouraging findings are also 
Table 2 Nimotuzumab trials in NSCLC

\begin{tabular}{|c|c|c|c|c|c|c|c|c|c|}
\hline Authors & Phase & Location & $\begin{array}{l}\text { No. of } \\
\text { patients }\end{array}$ & Cancer & Dosage & ORR & DCR & MTP & OST \\
\hline Bebb et $a^{55}$ & 1 & Canada & 18 & NSCLC & $\begin{array}{l}\text { 7@100 mg; } \\
\text { 6@200 mg; } \\
\text { 5@400 mg }\end{array}$ & $66 \%^{\mathrm{a}}$ & $94 \%^{a}$ & $5.4 \mathrm{mo}^{\mathrm{b}}$ & $9.8 \mathrm{mo}^{\mathrm{c}}$ \\
\hline Choi et al ${ }^{56}$ & I & Korea & 15 & NSCLC & $\begin{array}{l}\text { 5@100 mg; } \\
\text { 5@200 mg; } \\
5 @ 400 \text { mg }\end{array}$ & $46.7 \%^{a}$ & $100 \%^{a}$ & $164 d^{d}$ & $298 d^{e}$ \\
\hline Macias et $\mathrm{al}^{58 \mathrm{f}}$ & II & Cuba & 21 & $\begin{array}{l}\text { NSCLC brain } \\
\text { metastases }\end{array}$ & $200 \mathrm{mg}$ & & $91.6 \%$ & & \\
\hline
\end{tabular}

Notes: a ORR and DCR within radiation field; ${ }^{\mathrm{9}} 95 \% \mathrm{Cl}, 0.9-9.9$ months; ${ }^{\mathrm{c}} 95 \% \mathrm{Cl}, 6.5-13.1$ months; ${ }^{\mathrm{d}} 95 \% \mathrm{Cl}, 26-302$ days; ${ }^{\mathrm{e}} 95 \% \mathrm{Cl}$, $199-397$ days; ${ }^{\mathrm{f}} \mathrm{Based}$ on preliminary results.

Abbreviations: NSCLC, non-small cell lung cancer; ORR, objective response rate; DCR, disease control rate; MST, median survival time; OST, overall survival time; $\mathrm{Cl}$, confidence interval.

now underway and recruiting in North America and South Africa.

\section{The anti-EGFR side-effect profile}

EGFR targeting TKIs and mAbs has been associated with several side effects, especially within organs with high levels of proliferation and EGFR expression, most notably the epidermis and intestinal lining. These include grade 3 and 4 severe adverse events that can significantly impact a patient's quality of life and result in a reduction or cessation of continued treatment. The dermatological reaction has been extensively described as an acneiform rash (although this term may be inaccurate $)^{59}$ and is present in up to $90 \%$ of mAb-treated cases, ${ }^{60} 38 \%$ of which are grade 3 or 4 reactions. ${ }^{61}$ Furthermore, experience in the head and neck cancer population suggests that the radiation-induced dermatitis and mucositis may be exacerbated by the addition of an anti-EGFR monoclonal antibody. ${ }^{62-65}$

In contrast, these side effects are rare in cases of nimotuzumab use and are mainly limited to grade 1 or 2 adverse events. ${ }^{66}$ Most conspicuously, the typical grade 3 or 4 skin toxicity found in other anti-EGFR drugs has thus far remained virtually absent in nimotuzumab trials. ${ }^{44}$ In fact, when nimotuzumab was tested for toxicity in the large mammal model Cercopithecus aethiops sabaeus (green monkeys), it was found to not display any dermatological side effects, even at doses 10 times the amount recommended for human use. ${ }^{36}$ The cutaneaous manifestations of nimotuzumab treatment were investigated in the recently completed Korean Phase I trial ${ }^{56}$ in which skin biopsies from a clinically normal skin area were collected before the first dose of nimotuzumab and after 2-8 weeks of treatment from 10 patients in the 200 and $400 \mathrm{mg}$ cohorts. Histologically, the characteristic thinning of the stratum corneum and folliculitis induced by other EGFR inhibitors was not observed, whereas at the molecular level, nimotuzumab did not suppress EGFR phosphorylation, receptor signaling, or keratinocyte proliferation (Ki-67), ${ }^{56}$ echoing findings in a head and neck cancer trial. ${ }^{67}$ Nimotuzumab's benign side-effect profile is not limited to the epidermis though, as it also includes the absence of severe hypomagnesemia and a lack of grade 3 or 4 gastrointestinal side effects, commonly seen in this class of agents. ${ }^{68,69}$

The pharmacokinetic mechanism for why nimotuzumab seems to have similar antitumor activity to other EGFRtargeted mAbs without the severe side effects could be its intermediate binding affinity. Decreased affinity to EGFR allows for an optimal dose of nimotuzumab that is below the toxic dose. Experimental mathematical models have predicted that for anti-EGFR mAbs to balance maximal tumor targeting with minimal normal cell toxicity, the binding affinity $(\mathrm{Kd})$ should be in the range of $10^{-8}-10^{-9}$ M. ${ }^{70}$ Although nimotuzumab is within this range, cetuximab has a binding affinity 10 -fold stronger. It has more recently been hypothesized by Tikhomirov et $\mathrm{al}^{71}$ that in contrast to other in-class mAbs, mainly cetuximab and panitumumab, nimotuzumab's capacity to bind EGFR is heavily dictated by cell surface receptor density. This is attributed to the difference between monovalent and bivalent binding of nimotuzumab, which is transiently bound monovalently, and strongly bound bivalently to EGFR epitopes. ${ }^{71}$ In normal cells (eg, skin epithelial cells), EGFR expression is too low to cause nimotuzumab bivalent binding, therefore avoiding unwanted skin toxicities. Overexpressing tumor cells, on the other hand, will have enough receptor density for nimotuzumab to bind bivalently and robustly inhibit the EGFR. ${ }^{71,72}$ Whatever the reason, the absence of severe toxicity especially the skin rash could be a critical clinical 
bonus if nimotuzumab is shown to be efficacious in Phase II trials in NSCLC.

\section{Nimotuzumab predictive markers}

The paradigm of molecularly directed treatment, well defined in the world of leukemia and lymphoma, is also established in certain solid tumors such as breast cancer, where estrogen and progesterone receptor positivity has long-guided treatment and HER2 testing has helped direct the use of trastuzumab. Even in the colorectal cancer (CRC) world, several recent Phase III studies have shown that $K$-ras mutations preclude benefit from anti-EGFR mAb therapy in metastatic CRC. ${ }^{73-75}$ The "realness" of this effect is supported by its demonstration in several line settings, with more than one anti-EGFR mAb, and when such an agent is used alone or in combination with chemotherapy. In a small Phase II trial of nimotuzumab with irinotecan in refractory $\mathrm{CRC}$, there was a difference in overall survival between patients whose tumors were $K$-ras wild type compared with those with $K$-ras mutant tumors, suggesting that $K$-ras status may also be relevant in nimotuzumab use in CRC. ${ }^{76}$ However, this phenomenon does not seem to extend to NSCLC. Disappointingly, the role of $K$-ras as a predictive marker for the use of the anti-EGFR mAb cetuximab with platinum-based systemic treatment in stage-IV NSCLC was recently discredited in the FLEX study, ${ }^{77}$ which suggested that $K$-ras status is not a predictor of response to these agents in the treatment of metastatic NSCLC. ${ }^{78}$

Attempts at finding predictive markers specifically for nimotuzumab have to date not been forthcoming. Molecular determinants of response were investigated in both Phase I trials of nimotuzumab with palliative radiation in NSCLC. Markers investigated were EGFR status by immunohistochemistry, EGFR gene copy number by fluorescence in situ hybridization analysis, and K-ras mutational status by sequencing. However, the paucity of high-quality biopsy material meant that only 10 of 18 patients in the Canadian study and 5 of 15 patients in the Korean study had tissue available for molecular interrogation, and so, no clear molecular correlates could be established in either study. This is not unusual in lung cancer; a low proportion of analyzable samples is a conspicuous feature of all NSCLC trials that include molecular correlative studies in their design and sometimes leads to over interpretation of the significance of predictive molecular markers. ${ }^{79,80}$

Several explanations have been put forward to account for the difference in significance of K-ras mutations in NSCLC compared with CRC. An understudied factor may be the relative magnitude of the immune-modulatory effect of anti-EGFR mAbs in NSCLC compared with CRC. It has been demonstrated that the in vitro extent of cetuximabmediated lysis of HNSCC cells is influenced not only by EGFR expression and cetuximab concentration but also by Fc $\gamma \mathrm{R}$ polymorphism. ${ }^{81} \mathrm{Fc} \gamma \mathrm{R}$ polymorphisms have also been implicated in conferring different survival in CRC patients, even in those with $K$-ras mutation-bearing tumors. ${ }^{82,83}$ These studies strongly suggest that immune factors play a role in determining anti-EGFR $\mathrm{mAb}$ response irrespective of $K$-ras status. The relative magnitude of this effect in the efficacy of each anti-EGFR mAb is unknown. Future trials of these agents, including nimotuzumab, must incorporate attempts to better quantify this effect in NSCLC.

A second issue may be the very nature and role of $K$-ras mutations in NSCLC compared with CRC. Revisiting intriguing observations from the $1990 \mathrm{~s}^{84}$ suggests that $K$-ras mutations differ in NSCLC compared with CRC in several ways, such as being less common (21\% vs 39\%), virtually absent in squamous cell tumors, more likely to be smoking associated (69\% vs 38\%), and more likely to be a transversion rather than a transition (3.0 vs 0.8 ). The relative importance of $K$-ras in each tumor must also be considered. It has been suggested that the PI3 K pathway assumes a greater importance in NSCLC than in CRC, thereby diminishing the role of $K$-ras in this setting.

\section{Visions of nimotuzumab's role in NSCLC management}

As mentioned, a classic challenge of NSCLC management is that patients typically present in a disadvantaged condition. Median age at presentation is in the late 60's and often comes with several comorbidities, a $33 \%$ probability of chronic obstructive pulmonary disease alone, and a performance status of 1 or more. ${ }^{85}$ Consequently, a large proportion of NSCLC patients is restricted in the degree of radical treatment they can undergo, if any at all, not just by the stage of their cancer but by their overall health. Unpublished analysis at our own center suggests that only $23 \%$ of stage-IV NSCLC patients actually receive systemic treatment. In end-of-life circumstances where palliation and quality of life are the ultimate objectives, a systemic therapeutic agent that can be used with minimal toxicity is obviously desirable. Nimotuzumab clearly fills these criteria but needs level I evidence based on randomized Phase III trials to support its use.

Adding a benign systemic treatment to palliative radiation in individuals deemed too weak to receive standard cytotoxic therapy would also be quite attractive. The relationship between ionizing radiation and EGFR remains 
intriguing. If, as proposed, radiation therapy increases EGFR cell surface concentrations and nimotuzumab activity is EGFR concentration dependent, ${ }^{21}$ then its activity should be more profound when used in conjunction with radiotherapy. ${ }^{86}$ Additionally, in locally advanced cases where combined modality treatment results in long-term remission in only $15 \%-20 \%$, the possibility of adding a well-tolerated, targeted systemic agent is welcomed. The presently enrolling Phase II protocols in this setting will confirm whether nimotuzumab is as promising as preclinical and Phase I results suggest.

Although there have yet to be trials that test nimotuzumab with chemotherapy in NSCLC, it also holds the potential to be a beneficial treatment paradigm. The possibility of achieving the same effect as cetuximab in the first-line setting in stage-IV NSCLC but with minimal toxicity is of course alluring. At present, a Japanese study is enrolling patients for a Phase II examination of nimotuzumab with docetaxel in chemotherapy-refractory or resistance advanced NSCLC.

Unfortunately, as single agents, anti-EGFR therapeutics might be beneficial in the short-term, but inevitably tumors develop resistance to these drugs. It has been postulated that a significant mechanism of resistance is the utilization of alternate receptor pathways, such as the insulin-like growth factor-I receptor (IGF-IR) to bypass EGFR signaling blockage or acquired mutations to molecular targets, like is seen in TKIs with EGFRvIII transmutation. ${ }^{87-89}$ Combined therapy against EGFR and potential resistance pathways has shown efficacy in some cases ${ }^{88}$ and therapies targeting more than one signaling receptor. ${ }^{90}$ Future NSCLC treatment may include the use of nimotuzumab to target the extracellular domain of EGFR in concert with TKIs inhibiting the cytosolic kinase and other targeted therapies acting against cancerogenic and resistance pathways, including VEGF and IGF-IR. However, this type of multimodal management strategy is only in the preclinical and early phases of clinical development, and unfortunately, some early studies record surprisingly detrimental effects. ${ }^{91,92}$ Obviously, more investigations are needed before this becomes an established paradigm for nimotuzumab in NSCLC management.

\section{Summary}

Nimotuzumab is a humanized anti-EGFR mAb that has demonstrated promising efficacy in the treatment of several EGFR-expressing solid tumors. Its tolerability in NSCLC has been demonstrated in two Phase I trials at doses of up to $400 \mathrm{mg}$ in conjunction with external beam palliative radiation in both a Canadian and Korean population. Its utility in NSCLC will be demonstrated by ongoing Phase II trials. The most significant feature of nimotuzumab's clinical experience to date is an intriguingly profound absence of the cutaneous anti-EGFR toxicity that is so characteristic of other anti-EGFR mAbs. This phenomenon has been attributed to a density-dependent binding to EGFR-expressing cells and may underpin a more optimal therapeutic window when nimotuzumab is used in conjunction with ionizing radiation. A politically unfavorable site of origin has hindered investment and the participation of US-based centers in clinical trials, but the recent initiation of manufacturing process in India may overcome this challenge. Meanwhile it is possible that nimotuzumab will find a niche in some markets where it will be promoted as a minimally toxic, less expensive anti-EGFR $\mathrm{mAb}$. If the efficacy of this molecule compares favorably with other anti-EGFR mAbs in current clinical trials, then its lack of toxicity will make it a very attractive therapeutic agent indeed.

\section{Disclosure}

The authors report no conflicts of interest in this work.

\section{References}

1. Jemal A, Siegel R, Ward E, et al. Cancer statistics, 2008. CA Cancer J Clin. 2008;58(2):71-96.

2. Fry WA, Phillips JL, Menck HR. Ten-year survey of lung cancer treatment and survival in hospitals in the United States: a national cancer data base report. Cancer. 1999;86(9):1867-1876.

3. Edwards BK, Brown ML, Wingo PA, et al. Annual report to the nation on the status of cancer, 1975-2002, featuring population-based trends in cancer treatment. J Natl Cancer Inst. 2005;97(19):1407-1427.

4. Jemal A, Thun MJ, Ries LA, et al. Annual report to the nation on the status of cancer, 1975-2005, featuring trends in lung cancer, tobacco use, and tobacco control. J Natl Cancer Inst. 2008;100(23):1672-1694.

5. Towfighi A, Ovbiagele B, Saver JL. Therapeutic milestone: stroke declines from the second to the third leading organ- and disease-specific cause of death in the United States. Stroke. 2010;41(3):499-503.

6. Ettinger DS, Akerley W, Bepler G, et al. Non-small cell lung cancer. J Natl Compr Canc Netw. 2008;6(3):228-269.

7. Emery IF, Battelli C, Auclair PL, Carrier K, Hayes DM. Response to gefitinib and erlotinib in non-small cell lung cancer: a restrospective study. BMC Cancer. 2009;9:333.

8. American Cancer Society. Non-small cell lung cancer survival rates by stage. Available from: http://www.cancer.org/Cancer/Lung-Cancer-Non-SmallCell/DetailedGuide/lung-cancer-non-small-cell-survivalrates. Published 2009. Accessed Jul 13, 2010.

9. Molina JR, Yang P, Cassivi SD, Schild SE, Adjei AA. Non-small cell lung cancer: epidemiology, risk factors, treatment, and survivorship. Mayo Clin Proc. 2008:83(5):584-594.

10. Lu HS, Chai JJ, Li M, Huang BR, He CH, Bi RC. Crystal structure of human epidermal growth factor and its dimerization. J Biol Chem. 2001;276(37):34913-34917.

11. Bennett CF, Mirejovsky D, Crooke RM, et al. Structural requirements for cationic lipid mediated phosphorothioate oligonucleotides delivery to cells in culture. J Drug Target. 1998;5(3):149-162.

12. Woodburn JR. The epidermal growth factor receptor and its inhibition in cancer therapy. Pharmacol Ther. 1999;82(2-3):241-250. 
13. Grandis JR, Sok JC. Signaling through the epidermal growth factor receptor during the development of malignancy. Pharmacol Ther. 2004; 102(1):37-46.

14. Lu Z, Jiang G, Blume-Jensen P, Hunter T. Epidermal growth factorinduced tumor cell invasion and metastasis initiated by dephosphorylation and downregulation of focal adhesion kinase. Mol Cell Biol. 2001; 21(12):4016-4031.

15. Kassis J, Lauffenburger DA, Turner T, Wells A. Tumor invasion as dysregulated cell motility. Semin Cancer Biol. 2001;11(2):105-117.

16. Rivera F, Vega-Villegas ME, Lopez-Brea MF. Cetuximab, its clinical use and future perspectives. Anticancer Drugs. 2008;19(2):99-113.

17. Pao W, Miller V, Zakowski M, et al. EGF receptor gene mutations are common in lung cancers from "never smokers" and are associated with sensitivity of tumors to gefitinib and erlotinib. Proc Natl Acad Sci US A. 2004;101(36):13306-13311.

18. Lynch TJ, Bell DW, Sordella R, et al. Activating mutations in the epidermal growth factor receptor underlying responsiveness of nonsmall-cell lung cancer to gefitinib. $N$ Engl J Med. 2004;350(21): 2129-2139.

19. Nicholson RI, Gee JMW, Harper ME. EGFR and cancer prognosis. Eur J Cancer. 2001;37 Suppl 4:S9-S15.

20. Navolanic PM, Steelman LS, McCubrey JA. EGFR family signaling and its association with breast cancer development and resistance to chemotherapy (review). Int J Oncol. 2003;22(2):237-252.

21. Akashi Y, Okamoto I, Iwasa T, et al. Enhancement of the antitumor activity of ionising radiation by nimotuzumab, a humanised monoclonal antibody to the epidermal growth factor receptor, in non-small cell lung cancer cell lines of differing epidermal growth factor receptor status. Br J Cancer. 2008;98(4):749-755.

22. Fukuoka M, Yano S, Giaccone G, et al. Multi-institutional randomized phase II trial of gefitinib for previously treated patients with advanced non-small-cell lung cancer. J Clin Oncol. 2003;21(12):2237-2246.

23. Shepherd FA, Rodrigues Pereira J, Ciuleanu T, et al. Erlotinib in previously treated non-small-cell lung cancer. $N$ Engl J Med. 2005; 353(2):123-132.

24. Paez JG, Janne PA, Lee JC, et al. EGFR mutations in lung cancer: correlation with clinical response to gefitinib therapy. Science. 2004; 304(5676):1497-1500.

25. Price DK, Figg WD. Mutations in the EGFR: the importance of genotyping. Cancer Biol Ther. 2004;3(5):434-435.

26. Ho C, Murray N, Laskin J, Melosky B, Anderson H, Bebb G. Asian ethnicity and adenocarcinoma histology continues to predict response to gefitinib in patients treated for advanced non-small cell carcinoma of the lung in North America. Lung Cancer. 2005;49(2):225-231.

27. Mok TS, Wu YL, Thongprasert S, et al. Gefitinib or carboplatinpaclitaxel in pulmonary adenocarcinoma. $N$ Engl J Med. 2009;361(10): 947-957.

28. Mitsudomi T, Morita S, Yatabe Y, et al. Gefitinib versus cisplatin plus docetaxel in patients with non-small-cell lung cancer harbouring mutations of the epidermal growth factor receptor (WJTOG3405): an open label, randomised phase 3 trial. Lancet Oncol. 2010;11(2):121-128.

29. Giaccone G, Herbst RS, Manegold C, et al. Gefitinib in combination with gemcitabine and cisplatin in advanced non-small-cell lung cancer: a phase III trial - INTACT 1. J Clin Oncol. 2004;22(5):777-784.

30. Plosker GL, Figgitt DP. Rituximab: a review of its use in non-Hodgkin's lymphoma and chronic lymphocytic leukaemia. Drugs. 2003;63(8): 803-843.

31. Ferrara N, Hillan KJ, Novotny W. Bevacizumab (Avastin), a humanized anti-VEGF monoclonal antibody for cancer therapy. Biochem Biophys Res Commun. 2005;333(2):328-335.

32. Li S, Schmitz KR, Jeffrey PD, Wiltzius JJ, Kussie P, Ferguson KM. Structural basis for inhibition of the epidermal growth factor receptor by cetuximab. Cancer Cell. 2005;7(4):301-311.

33. Kim S, Grandis JR, Rinaldo A, Takes RP, Ferlito A. Emerging perspectives in epidermal growth factor receptor targeting in head and neck cancer. Head Neck. 2008;30(5):667-674.
34. Mateo C, Moreno E, Amour K, Lombardero J, Harris W, Perez R. Humanization of a mouse monoclonal antibody that blocks the epidermal growth factor receptor: recovery of antagonistic activity. Immunotechnology. 1997;3(1):71-81.

35. Talavera A, Martínez C, Friemann R, et al. Modeling the interaction between the anti-tumor antibody h-R3 and its target, the epidermal growth factor receptor. Available from: www.ymbiosciences.com/ upload_files/pub_nimo_oslo_2007_talavera.pdf, 2007.

36. Arteaga ME, Ledon N, Casaco A, et al. Systemic and skin toxicity in Cercopithecus aethiops sabaeus monkeys treated during 26 weeks with a high intravenous dose of the anti-epidermal growth factor receptor monoclonal antibody nimotuzumab. Cancer Biol Ther. 2007; 6(9):1390-1395.

37. Crombet T, Torres L, Neninger E, Catala M, Solano ME, Perera A, et al. Pharmacological evaluation of humanized anti-epidermal growth factor receptor, monoclonal antibody h-R3, in patients with advanced epithelial-derived cancer. J Immunother. 2003;26(2):139-148.

38. Diaz Miqueli A, Blanco R, Garcia B, et al. Biological activity in vitro of anti-epidermal growth factor receptor monoclonal antibodies with different affinities. Hybridoma (Larchmt). 2007;26(6):423-431.

39. Crombet-Ramos T, Rak J, Perez R, Viloria-Petit A. Antiproliferative, antiangiogenic and proapoptotic activity of h-R3: a humanized antiEGFR antibody. Int $J$ Cancer. 2002;101(6):567-575.

40. Viloria-Petit A, Crombet T, Jothy S, et al. Acquired resistance to the antitumor effect of epidermal growth factor receptor-blocking antibodies in vivo: a role for altered tumor angiogenesis. Cancer Res. 2001;61(13):5090-5101.

41. Baumann M, Krause M, Dikomey E, et al. EGFR-targeted anti-cancer drugs in radiotherapy: preclinical evaluation of mechanisms. Radiother Oncol. 2007;83(3):238-248.

42. Bier H, Hoffmann T, Haas I, van Lierop A. Anti-(epidermal growth factor) receptor monoclonal antibodies for the induction of antibodydependent cell-mediated cytotoxicity against squamous cell carcinoma lines of the head and neck. Cancer Immunol Immunother. 1998;46(3): 167-173.

43. YM_BioSciences. Nimotuzumab: Science. Available from: http:// www.ymbiosciences.com/products/nimotuzumab/science.php. Published 2010

44. Boland WK, Bebb G. Nimotuzumab: a novel anti-EGFR monoclonal antibody that retains anti-EGFR activity while minimizing skin toxicity. Expert Opin Biol Ther. 2009;9(9):1199-1206.

45. You B, Brade A, Magalhaes JM, et al. A dose-escalation phase I trial of nimotuzumab, an antibody against the epidermal growth factor receptor, in patients with advanced solid malignancies. Invest New Drugs. 2010 May 8. [Epub ahead of print].

46. Winquist E, Nabid A, Sicheri D, et al. A phase I dose escalation study of a humanized monoclonal antibody to EGFR (hR3) in patients with locally advanced squamous cell cancer of the head and neck (SCCHN) treated with radiotherapy (RT). Proc Am Soc Clin Oncol. 2002;21. Abstract 926.

47. Rojo F, Gracias E, Villena N, et al. Pharmacodynamic study of nimotuzumab, an anti-epidermal growth factor receptor (EGFR) monoclonal antibody $(\mathrm{mAb})$, in patients with unresectable squamous cell carcinoma of the head and neck (SCCHN): a SENDO Foundation study. J Clin Oncol. 2008;26. Abstract 6070.

48. Reddy BK, Vidyasagar M, Shenoy K, et al. Nimotuzumab (h-R3) in combination with chemoradiotherapy and radiotherapy in the treatment of squamous cell carcinoma of head and neck (SCCHN). Available from: http://astro2007.abstractsnet.com/handouts/500467_Biocon_h-R3.pdf, 2007.

49. Rodriguez MO, Rivero TC, del Castillo Bahi D, et al. Nimotuzumab plus radiotherapy for unresectable squamous-cell carcinoma of the head and neck. Cancer Biol Ther. 2010;9(5):343-349.

50. Casaco A, Lopez G, Garcia I, et al. Phase I single-dose study of intracavitary-administered nimotuzumab labeled with $188 \mathrm{Re}$ in adult recurrent high-grade glioma. Cancer Biol Ther. 2008;7(3):333-339. 
51. Lam C, Bouffet E, Bartels U. Nimotuzumab in pediatric glioma. Future Oncol. 2009;5(9):1349-1361.

52. Reddy BK, Vidyasagar MS, Koteshwar R, et al. A phase IIb 4-arm open-label randomized study to assess the safety and efficacy of h-R3 monoclonal antibody against EGFR in combination with chemoradiation therapy or radiation therapy in patients with advanced (stage III or IVA) inoperable head and neck cancer. J Clin Oncol. 2009;27(15s Suppl). Abstract 6041.

53. Ramakrishnan MS, Eswaraiah A, Crombet T, et al. Nimotuzumab, a promising therapeutic monoclonal for treatment of tumors of epithelial origin. MAbs. 2009;1(1):41-48.

54. YM_BioSciences. Nimotuzumab: Clinical Trials. Available from: http:// www.ymbiosciences.com/products/nimotuzumab/clinical_trials.php. Accessed Jun 8, 2010.

55. Bebb G, Smith C, Rorke S, et al. Phase I clinical trial of the anti-EGFR monoclonal antibody nimotuzumab with concurrent external thoracic radiotherapy in Canadian patients diagnosed with stage IIb, III or IV non-small cell lung cancer unsuitable for radical therapy. Cancer Chemother Pharmacol. 2010 Jun 20. [Epub ahead of print].

56. Choi HJ, Sohn JH, Lee CG, et al. A phase I study of nimotuzumab in combination with radiotherapy in stages IIB-IV non-small cell lung cancer unsuitable for radical therapy: Korean results. Lung Cancer. 2010 May 5 [Epub ahead of print].

57. Fairchild A, Harris K, Barnes E, et al. Palliative thoracic radiotherapy for lung cancer: a systematic review. J Clin Oncol. 2008;26(24): 4001-4011.

58. Macias A, Neninger E, Santiesteban E, et al. Preliminary results of a phase II clinical trial of the anti-EGFR monoclonal antibody nimotuzumab in combination with whole brain radiation therapy in patients diagnosed with advanced non-small cell lung cancer (NSCLC) and unresectable brain metastases. Paper presented at: EORTC-NCI-AACR Annual Meeting; 2008; Geneva, Switzerland.

59. Agero AL, Dusza SW, Benvenuto-Andrade C, Busam KJ, Myskowski P, Halpern AC. Dermatologic side effects associated with the epidermal growth factor receptor inhibitors. J Am Acad Dermatol. 2006;55(4):657-670.

60. van Cutsem E, Peeters M, Siena S, et al. Open-label phase III trial of panitumumab plus best supportive care compared with best supportive care alone in patients with chemotherapy-refractory metastatic colorectal cancer. J Clin Oncol. 2007;25(13):1658-1664.

61. Hu JC, Sadeghi P, Pinter-Brown LC, Yashar S, Chiu MW. Cutaneous side effects of epidermal growth factor receptor inhibitors: clinical presentation, pathogenesis, and management. $J$ Am Acad Dermatol. 2007;56(2):317-326.

62. Giro C, Berger B, Bolke E, et al. High rate of severe radiation dermatitis during radiation therapy with concurrent cetuximab in head and neck cancer: results of a survey in EORTC institutes. Radiother Oncol. 2009; 90(2):166-171.

63. Merlano M, Occelli M. Review of cetuximab in the treatment of squamous cell carcinoma of the head and neck. Ther Clin Risk Manag. 2007;3(5):871-876.

64. Merlano M, Garrone O. Treatment of advanced head and neck cancer with cetuximab. Int J Biol Markers. 2007;22(1 Suppl 4):S71-S76.

65. Bonner JA, Ang K. More on severe cutaneous reaction with radiotherapy and cetuximab. N Engl J Med. 2007;357(18):1872-1873; author reply 1873 .

66. Crombet T, Figueredo J, Catala M, et al. Treatment of high-grade glioma patients with the humanized anti-epidermal growth factor receptor (EGFR) antibody h-R3: report from a phase I/II trial. Cancer Biol Ther. 2006;5(4):375-379.

67. Rojo F, Gracias E, Villena N, et al. Pharmacodynamic trial of nimotuzumab in unresectable squamous cell carcinoma of the head and neck: a SENDO Foundation study. Clin Cancer Res. 2010;16(8):2474-2482.

68. Tejpar S, Piessevaux H, Claes K, et al. Magnesium wasting associated with epidermal-growth-factor receptor-targeting antibodies in colorectal cancer: a prospective study. Lancet Oncol. 2007;8(5):387-394.
69. Giusti RM, Cohen MH, Keegan P, Pazdur R. FDA review of a panitumumab (Vectibix) clinical trial for first-line treatment of metastatic colorectal cancer. Oncologist. 2009;14(3):284-290.

70. Crombet T, Osorio M, Cruz T, et al. Use of the humanized anti-epidermal growth factor receptor monoclonal antibody h-R3 in combination with radiotherapy in the treatment of locally advanced head and neck cancer patients. J Clin Oncol. 2004;22(9):1646-1654.

71. Tikhomirov I, Garrido G, Yang E, Sherman I, Perez R. Bivalent binding properties of epidermal growth factor receptor (EGFR) targeted monoclonal antibodies: factors contributing to differences in observed clinical profiles. AACR Cancer Clinical Trials and Personalized Medicine. 2008. Abstract A36.

72. Garrido G, Rabasa A, Gracia E, et al. Binding properties of the antiEGFR monoclonal antibody, nimotuzumab, limit its interaction with the EGFR in renal and epidermal cells. Paper presented at: AACR 100th Annual Meeting; 2009; San Diego, CA. Abstract 2763.

73. Vale C, Tierney JF, Meade A, et al. Impact of K-ras status on the effects of EGFR-targeted monoclonal antibody (MAb) therapy in advanced colorectal cancer (ACRC): A systematic review and meta-analysis of randomized controlled trials (RCTs). J Clin Oncol. 2009;27 Suppl 15: 4122. In: Proceedings of ASCO Annual Meeting. 2009; Alexandria, VA. Abstract 4122.

74. Amado RG, Wolf M, Peeters M, et al. Wild-type KRAS is required for panitumumab efficacy in patients with metastatic colorectal cancer. J Clin Oncol. 2008;26(10):1626-1634.

75. Karapetis CS, Khambata-Ford S, Jonker DJ, et al. K-ras mutations and benefit from cetuximab in advanced colorectal cancer. $N$ Engl J Med. 2008;359(17): 1757-1765.

76. Shah AM, Chen E, Jonker D, et al. A Phase II clinical trial of nimotuzumab, an EGFR monoclonal antibody (MAb), in metastatic colorectal cancer (mCRC). J Clin Oncol. 2009. In: Proceedings of ASCO GI symposium; 2009; Alexandria, VA. Abstract 358.

77. Pirker R, Pereira JR, Szczesna A, et al. Cetuximab plus chemotherapy in patients with advanced non-small-cell lung cancer (FLEX): an openlabel randomised phase III trial. Lancet. 2009;373(9674):1525-1531.

78. O'Byrne KJ, Bondarenko I, Barrios C, et al. Molecular and clinical predictors of outcome for cetuximab in non-small cell lung cancer(NSCLC): data from the FLEX study. J Clin Oncol. 2009; 27 Suppl 15. Abstract 8007.

79. Loriot Y, Mordant P, Deutsch E, Olaussen KA, Soria JC. Are RAS mutations predictive markers of resistance to standard chemotherapy? Nat Rev Clin Oncol. 2009;6(9):528-534.

80. Linardou H, Dahabreh IJ, Kanaloupiti D, et al. Assessment of somatic k-RAS mutations as a mechanism associated with resistance to EGFRtargeted agents: a systematic review and meta-analysis of studies in advanced non-small-cell lung cancer and metastatic colorectal cancer. Lancet Oncol. 2008;9(10):962-972.

81. López-Albaitero A, Steve CL, Morgan S. Role of polymorphic Fc gamma receptor IIIa and EGFR expression level in cetuximab mediated, NK cell dependent in vitro cytotoxicity of head and neck squamous cell carcinoma cells. Cancer Immunol Immunother. 2009; 58(11):1855-1864.

82. Bibeau F, Lopez-Crapez E, Di Fiore F, et al. Impact of Fc $\{$ gamma $\}$ RIIaFc $\{$ gamma $\}$ RIIIa polymorphisms and KRAS mutations on the clinical outcome of patients with metastatic colorectal cancer treated with cetuximab plus irinotecan. J Clin Oncol. 2009;27(7):1122-1129.

83. Oden-Gangloff A, Di Fiore F, Bibeau F, et al. TP53 mutations predict disease control in metastatic colorectal cancer treated with cetuximabbased chemotherapy. Br J Cancer. 2009;100(8):1330-1335.

84. Mack PC, Gandara DR, Omori A, et al. KRAS mutation analysis in NSCLC versus colorectal cancer (CRC): implications for EGFRdirected therapies. Paper presented at: IASLC World Conference on Lung Cancer; 2009; San Francisco, CA.

85. Yang P, Allen MS, Aubry MC, et al. Clinical features of 5,628 primary lung cancer patients: experience at Mayo Clinic from 1997 to 2003. Chest. 2005;128(1):452-462. 
86. Diaz Miqueli A, Rolff J, Lemm M, Fichtner I, Perez R, Montero E. Radiosensitisation of U87MG brain tumours by anti-epidermal growth factor receptor monoclonal antibodies. Br J Cancer. 2009;100(6): 950-958.

87. Kobayashi S, Boggon TJ, Dayaram T, et al. EGFR mutation and resistance of non-small-cell lung cancer to gefitinib. $N$ Engl J Med. 2005;352(8):786-792.

88. Kim H-P, Han S-W, Kim S-H, et al. Combined lapatinib and cetuximab enhance cytotoxicity against gefitinib-resistant lung cancer cells. $\mathrm{Mol}$ Cancer Ther. 2008;7(3):607-615.

89. Morgillo F, Kim W-Y, Kim ES, Ciardiello F, Hong WK, Lee H-Y. Implication of the insulin-like growth factor-IR pathway in the resistance of non-small cell lung cancer cells to treatment with gefitinib. Clin Cancer Res. 2007;13(9):2795-2803.
90. Kaulfuß, S, Burfeind P, Gaedcke J, and Scharf J-G. Dual silencing of insulin-like growth factor-I receptor and epidermal growth factor receptor in colorectal cancer cells is associated with decreased proliferation and enhanced apoptosis. Mol Cancer Ther. 2009;8(4):821-833.

91. Bartolome RA, Ferreiro S, Miquilena-Colina ME, et al. The chemokine receptor CXCR4 and the metalloproteinase MT1-MMP are mutually required during melanoma metastasis to lungs. Am J Pathol. 2009; 174(2):602-12.

92. Punt CJA, Tol J. More is less - combining targeted therapies in metastatic colorectal cancer. Nat Rev Clin Oncol. 2009;6(12):731-733.

\section{Publish your work in this journal}

Biologics: Targets \& Therapy is an international, peer-reviewed journal focusing on the patho-physiological rationale for and clinical application of Biologic agents in the management of autoimmune diseases, cancers or other pathologies where a molecular target can be identified. This journal is indexed on PubMed Central, CAS, EMBase, Scopus

\section{Dovepress}

and the Elsevier Bibliographic databases. The manuscript management system is completely online and includes a very quick and fair peerreview system, which is all easy to use. Visit http://www.dovepress. com/testimonials.php to read real quotes from published authors. 